\title{
Strong Genetic Differentiation among Neighboring Populations of a Locally Endemic Primrose
}

Author(s): Lee Bjerregaard and Paul G. Wolf

Source: Western North American Naturalist, 68(1):66-75. 2008.

Published By: Monte L. Bean Life Science Museum, Brigham Young University

DOI: http://dx.doi.org/10.3398/1527-0904(2008)68[66:SGDANP]2.0.CO;2

URL: http://www.bioone.org/doi/full/10.3398/1527-0904\%282008\%2968\%5B66\%3ASGDANP

$\% 5 \mathrm{D} 2.0 . \mathrm{CO} \% 3 \mathrm{~B} 2$

BioOne (www.bioone.org) is a nonprofit, online aggregation of core research in the biological, ecological, and environmental sciences. BioOne provides a sustainable online platform for over 170 journals and books published by nonprofit societies, associations, museums, institutions, and presses.

Your use of this PDF, the BioOne Web site, and all posted and associated content indicates your acceptance of BioOne's Terms of Use, available at www.bioone.org/page/terms of use.

Usage of BioOne content is strictly limited to personal, educational, and non-commercial use. Commercial inquiries or rights and permissions requests should be directed to the individual publisher as copyright holder. 
Western North American Naturalist 68(1), (C) 2008, pp. 66-75

\title{
STRONG GENETIC DIFFERENTIATION AMONG NEIGHBORING POPULATIONS OF A LOCALLY ENDEMIC PRIMROSE
}

\author{
Lee Bjerregaard ${ }^{1}$ and Paul G. Wolf ${ }^{1,2}$
}

\begin{abstract}
Maguire primrose is a locally endemic plant of northern Utah, USA, with a total known range of less than $20 \mathrm{~km}^{2}$. A previous study found evidence for strong differentiation among local populations at 4 allozyme loci. Here we reexamined populations using 165 AFLP loci and found further evidence of unusually strong genetic structure. We also found an apparently fixed nucleotide difference between populations for a noncoding region of chloroplast DNA, mirroring the patterns seen for AFLP loci. Furthermore, we tested the hypothesis that the current population structure is the result of breeding barriers between plants from different populations. We made controlled hand-pollinated crosses and found that interpopulation crosses did not set significantly fewer seeds than intrapopulation crosses. Thus, we found no evidence of breeding barriers to explain these genetic patterns. However, we did note a relatively short overlap in flowering time, suggesting that phenology is a more feasible explanation for genetic differentiation than pollen-stigma incompatibility. Our study emphasizes that even locally endemic plants can house measurable genetic differences over a short geographic scale.
\end{abstract}

Key words: Primula, AFLP, allozyme, pollination, breeding system, endemism.

Geographically widespread taxa should harbor more genetic diversity than their narrowly distributed relatives (Hamrick and Godt 1996, Maki et al. 1999). Widespread taxa usually comprise more individuals and are likely to be older than narrowly distributed taxa, thereby providing more opportunity to attain and maintain diversity (Nei et al. 1975). Furthermore, patterns of population subdivision are expected to be a function of species range. In theory, degree of genetic subdivision should be a function of distance between populations, because increased distance reduces the probability of gene flow. However, recent surveys indicate that these generalizations about genetic diversity and population subdivision are not warranted. Gitzendanner and Soltis (2000) found no correlations, or very weak correlations, between rarity and various population genetic statistics, after accounting for other variables including phylogenetic history. It is, however, unusual to find a narrowly distributed outcrossing species with populations that are highly structured. Here, we examine such an example in an attempt to explain the origin of its population structure.

Maguire primrose is listed as a threatened species (U.S. Fish and Wildlife Service 1985) endemic to a narrow corridor of Logan Canyon in northern Utah, USA (Fig. 1). The species is a perennial herbaceous plant that blooms in early spring with purple to lavender flowers and a yellow inner corolla tube. Leaves form a basal rosette subtending the leafless flower scapes, which each have 1-3 flowers. Corolla lobes are about $2.5 \mathrm{~cm}$ across and stems are leafless, up to $15 \mathrm{~cm}$ high. Flowers are distylous with pin-thrum polymorphism, which is present in many Primula species and promotes outcrossing (Darwin 1877). Observed visitors of Maguire primrose are bees (Bombus; Beedlow et al. 1980, Wolf and Sinclair 1997) and flies (Padgett 1986). Maguire primrose is known from 6 locations comprising approximately 3000 individuals (Padgett 1986). The total range is approximately $19 \times 1 \mathrm{~km}$ with a $12-\mathrm{km}$ separation between populations near the mouth of Logan Canyon (hereafter referred to as the lower canyon group) and the remaining populations farther (east) up the canyon (hereafter referred to as the upper canyon group). The entire range spans elevations from 1400 to 1800 $\mathrm{m}$. Habitat requirements are specific to very shallow soils derived from dolomitic rock of the Laketown and Fish Haven geologic formations, and the plants may be physiologically dependent on the calcium and magnesium carbonates derived from the substrate (U.S. Fish and 


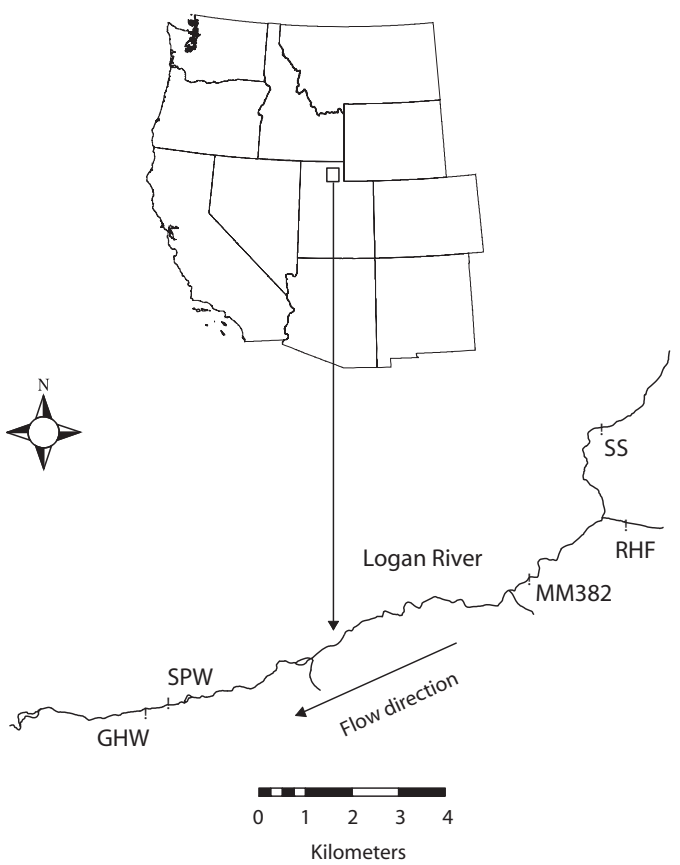

Fig. 1. Map showing the distribution and location of sampling sites for Maguire primrose. Full names of sites are given in the text. MM382 refers to milemarker 382 and is a population that was sampled in the 1997 allozyme study but was replaced here by RHF. SPW and GHW are in the lower canyon group, and SS and RHF are in the upper canyon group

Wildlife Service 1985). Maguire primrose is restricted to cool, moist microhabitats of slopes and ledges within Logan Canyon.

Maguire primrose was originally treated as Primula maguirei (Williams 1936), distinct from its close relative P. cusickiana A. Gray, found in southwestern Idaho and northeastern Oregon. Since the discovery of Maguire primrose, 2 other distinct but closely related forms have been discovered: $P$. nevadensis N.H. Holmgren in eastern Nevada and $P$. domensis Kass and S.L. Welsh in southeastern Utah. A recent revision lists these 4 primulas as varieties of $P$. cusickiana (Holmgren and Kelso 2001), each unique in its geographic range and ecological requirements. All these taxa are restricted to cool, wet habitats in arid regions of the Great Basin.

Because Maguire primrose likely requires an insect pollinator, one would expect to see some gene flow and therefore relatively little genetic differentiation, especially in light of the narrow range of the taxon. However, results from a pre- vious study revealed high genetic structuring for populations of Maguire primrose (Wolf and Sinclair 1997). Four of the 13 allozyme loci examined were fixed, or nearly fixed, for alternate alleles at opposite ends of the relatively short geographic range.

Wolf and Sinclair (1997) presented 2 hypotheses to explain the observed population subdivision: (1) Maguire primrose has undergone a population bottleneck, smaller than its present abundance, resulting in severe genetic drift, and (2) populations in the upper and lower canyon groups are adapted to different microhabitats. Here, we examine the 1st hypothesis and test additional hypotheses. Because only 4 of 13 loci used by Wolf and Sinclair (1997) exhibited strong population subdivision, we test whether the earlier results were a function of inadequate locus sampling and if different genetic patterns would be seen in a larger sample of loci. We also examine whether the apparent lack of gene flow over a short geographic distance is a function of breeding barriers between upper and lower canyon populations. We evaluate breeding ability as a function of flowering times at the different sites, and we test for pollen-stigma incompatibilities with controlled crosses between plants from the same and from different sites. We also compare populations of Maguire primrose for variation in slowly evolving chloroplast DNA sequences.

\section{Methods}

For the genetic survey, we sampled 106 individuals of Maguire primrose from 4 populations, 2 from the upper canyon group and 2 from the lower canyon group (Fig. 1). Populations sampled in the upper group were "Right Hand Fork" (RHF) and "Seed Source" (SS), and populations sampled in the lower group were "Green House Wall" (GHW) and "Second Practice Wall” (SPW). The sampling was similar to that of Wolf and Sinclair (1997) except that the population denoted "mile marker 382 " was replaced in this study by nearby $(1.6 \mathrm{~km}$ arc distance) population $\mathrm{RHF}$ in the upper canyon region. We sampled plants in spring 2002 at distances of 3-25 m between plants to avoid sampling closely related individuals.

DNA extraction followed the protocol of Doyle and Doyle (1987). The AFLP procedure was based on Vos et al. (1995) with minor modifications described elsewhere (Wolf et al. 2004). 
Each initial digestion-ligation reaction included $100 \mathrm{ng}$ DNA in a total volume of $50 \mu \mathrm{L}$. Three pairs of selective (plus-three) primers were used: $M s e-A C T$ and Eco-ACG, Mse-AGA and Eco-AGG, and Mse-CAG and Eco-ACC. EcoRI primers were labeled with a FAM fluorescent dye. Samples were electrophoresed on 5\% Long Ranger polyacrylamide gels using an ABI 377 DNA sequencer (Applied Biosystems, www.appliedbiosystems.com) for 3.5 hours. For each sample reaction, $0.75 \mu \mathrm{L}$ formamide, $0.15 \mu \mathrm{L}$ loading dye, and $0.30 \mu \mathrm{L}$ Genescan Rox 500 (Applied Biosystems) were mixed with $1.5 \mu \mathrm{L}$ of the selective PCR products and then denatured at $94^{\circ} \mathrm{C}$ for 2 minutes. Chromatograms were analyzed with GeneScan analysis software, version 3.1 (Applied Biosystems). Each band fragment was considered as a separate putative locus and scored as present (1) or absent $(0)$ using the software program Genographer (Benham et al. 1999). AFLP profiles ranging in size from 50 to $495 \mathrm{bp}$ were scored without knowledge of sample identity.

Reproducibility

To test the reproducibility of AFLP profiles, we randomly selected 16 samples (4 DNA samples from each of the 4 populations) and repeated the AFLP procedure. Each test sample was also run at 3 different DNA concentrations $\left(30 \mathrm{ng} \cdot \mu \mathrm{L}^{-1}, 100 \mathrm{ng} \cdot \mu \mathrm{L}^{-1}\right.$, and 200 ng $\cdot \mu \mathrm{L}^{-1}$ ) using the same 3 selective primer combinations as above. The sample identity remained unknown throughout the AFLP procedure and analysis. After analysis, the sample identity was revealed, and profiles were compared across treatments for each sample. An error rate was calculated from the number of mismatches for samples run on different gels, and for each different sample concentration. The error rate was calculated as follows:

mismatches / loci $\cdot$ replicates.

\section{Population Structure Analysis}

We examined population genetic differentiation visually by using principal component analysis (PCA) performed in NTSYS-pc software version 2.10t (Rholf 1989). We also generated a UPGMA dendrogram of individual plants based on AFLP profiles, using SPSS v. 13 for Windows (SPSS Inc., Chicago, IL). Because many analyses of dominant markers assume Hardy-Weinberg equilibrium, we sampled 4 codominant markers to test this assumption. We tested 4 allozyme loci for the same plants that were used in the AFLP study. Allozyme protocols followed Wolf and Sinclair (1997). We used the software Tools For Population Genetic Analysis (TFPGA; Miller 1997) to test the null hypothesis that genotypes are in Hardy-Weinberg proportions. We used an exact test of a conventional Monte Carlo method for genotype analysis, with 10 batches per analysis, 200 permutations per batch, and 2000 total permutations.

We prepared AFLP dominant marker data for AMOVA (Schneider et al. 2000) analysis using the program AMOVA-PREP version 1.1 (Miller 1997). This program prepares a pairwise Euclidean distance matrix and all necessary input files for AMOVA. A pairwise difference distance method was used to construct within- and among-population variation percentages and $\mathrm{F}_{\mathrm{ST}}$ (Weir and Cockerham 1984, Excoffier et al. 1992, Weir 1996). Standard deviations $(s)$ were estimated from 1000 bootstrap replicates.

\section{Chloroplast DNA Sequences}

A region of chloroplast DNA was sequenced using 4 samples randomly chosen from each of 4 populations. We used the primers developed by Taberlet et al. (1992) to sequence noncoding regions from the trnL (UAA) 5' exon through the trnL (UAA) 3' exon and from the $\operatorname{trnL}$ (UAA) 3' exon to $\operatorname{trnF}$ (GAA).

\section{Breeding Study}

A breeding system study was conducted to determine the possibility of reproductive barriers accounting for the genetic structuring of Maguire primrose. Significantly higher numbers of seeds set from intrapopulation crosses than from interpopulation crosses would be evidence for the existence of reproductive barriers that could reduce gene flow. Phenology was also monitored for each population to see if populations may be isolated by nonoverlapping flowering times.

Two populations were monitored for flowering times and used to perform hand-pollinated crosses. We used GHW at the lower canyon and RHF at the upper canyon. These populations were separated by $14 \mathrm{~km}$. Pollination bags were attached to plants at GHW at elevations of 1515-1677 m. Bagging was done 
Table 1. $P$-values from the conventional Monte Carlo method to test for Hardy-Weinberg equilibrium of 4 codominant allozyme loci.

\begin{tabular}{llccc}
\hline Locus & GHW & SPW & RHF & SS \\
\hline Aat & 0.425 & 1 & 0.4195 & 1 \\
Pgm-1 & 0.56 & 0.06 & fixed & fixed \\
Pgm-2 & fixed & fixed & 0.061 & 1 \\
Idh & fixed & 1 & fixed & fixed \\
\hline
\end{tabular}

from 13 April to 3 May 2004 and plants were pollinated from 22 April to 7 May 2004. At RHF, we used plants at elevations of 1640-1693 m. Plants were bagged from 19 April through 3 May 2004 and pollinated from 30 April to 14 May 2004. We recorded the total number of flowers available for treatment as a proxy for degree of flowering in the population.

We used sampling transects to guide selection of plants for treatment. However, we were not always able to follow a strict transect because of the rough terrain inhabited by Maguire primrose. Treated plants were at least $2 \mathrm{~m}$ apart from each other, with some exceptions at RHF, where fewer plants were available. We made 29 intrapopulation and 19 interpopulation crosses at GHW, and 20 intrapopulation and 22 interpopulation crosses at RHF.

We also attempted to test the ability of the plants to self-fertilize, as a control to ensure that seed set in cross-pollinated plants was indeed a function of crossing. Generally, studies of plant mating systems involving hand pollination avoid the possibility of selfing by emasculating flowers prior to anther dehiscence. However, emasculation can damage the plant and result in lower seed set (Motten 1982). Furthermore, many Primula species are unable to self-fertilize (Miller et al. 1994). For Maguire primrose, stigmas did not appear to be receptive during anthesis, but we nevertheless attempted to self-pollinate 5 plants. As an additional control, plants at each population were designated as bagged controls and were bagged but not hand pollinated to test for spontaneous seed set, presumably by selfing, but without treatment by hand or natural pollinators. Also, plants at each population were chosen to serve as open-controls for seed set and therefore were not bagged or hand pollinated but seeds were collected to get an estimate of seed set under natural conditions. Some pollination bags contained $>1$ inflorescence, but only seed set data from the uppermost inflorescence were used in the analysis.
Hand pollination for the cross-pollinated treatment was done by arbitrarily selecting available plants as pollen donors. Pollen transfer was done by removing an anther from a donor plant and touching it to the recipient stigma. Interpopulation crosses were always done by transport of the corolla and corolla tube to the recipient population. Times between pollen/corolla removal and pollination were kept similar among treatments. Due to distyly, all anthers had to be removed from a recipient thrum plant to allow for the placement of donor pollen on the stigma of a pin plant. A hand ocular lens was used to confirm the presence of pollen on the stigma. We then monitored plants for fruit development. Just prior to dehiscence, capsules were collected and seeds were counted. Plants that failed to set seed were still included in all calculations. A Student's $t$ test was used to compare seed set data from intra- and interpopulation crosses. All treatments were repeated with larger sample sizes in 2005, but no seed set was observed in any treatment, probably due to unseasonably cold weather during flowering time. We counted plants selected for treatment and recorded whether they were a pin or thrum morph.

\section{RESULTS}

\section{Population Structure Analysis}

AFLP analysis revealed 165 putative loci produced by the 3 selective primer combinations. Error rates were $<1 \%$. Of the 165 loci, 22 were monomorphic and 108 were polymorphic, with the rarest phenotype at a frequency of at least 0.1 . The remaining 35 loci were weakly polymorphic, with the rare phenotype at low frequencies. Levels of polymorphism within populations (again at the 0.1 criterion) were $50,51,37$, and 49 loci at populations GHW, SPW, SS, and RHF, respectively.

Genotype frequencies of allozyme loci appeared to be in Hardy-Weinberg proportions. The null hypothesis that Maguire primrose populations are in Hardy-Weinberg equilibrium could not be rejected based on $P$-values obtained from the conventional Monte Carlo analysis (Table 1). Therefore, if we extrapolate to dominant AFLP loci it seems reasonable to assume Hardy-Weinberg equilibrium.

PCA plots of the AFLP data revealed population differentiation between upper and lower 


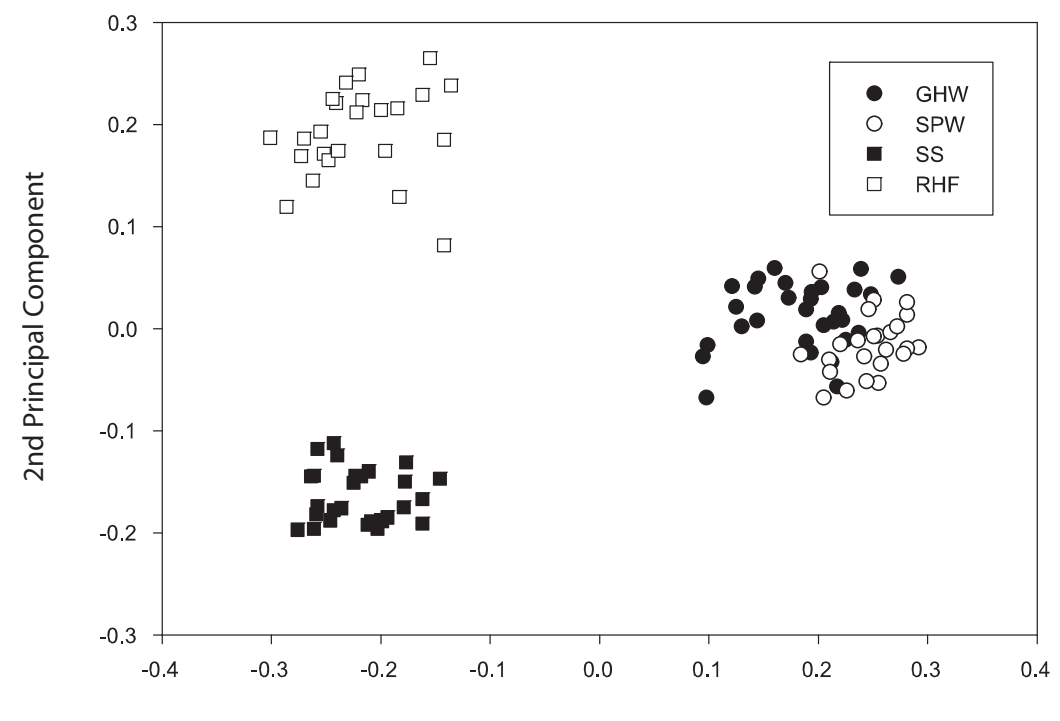

Ist Principal Component

Fig. 2. Principal components analysis of 165 AFLP loci for 4 populations of Maguire primrose. Squares denote plants in the upper canyon group and circles denote those in the lower canyon group.

canyon groups and between populations within the upper canyon (Fig. 2). Twenty-nine percent of the variance was captured by the first 2 principal components, which was sufficient to distinguish individuals at the lower canyon from those at the upper canyon. Likewise, there was a clear distinction between RHF and SS at the upper canyon. The distinction between the 2 lower canyon populations was not as clear but was still evident in the PCA plot. The UPGMA dendrogram (not shown) also supported the results of the PCA plot. Upper populations RHF and SS were genetically distinct, forming separate branches. Lower populations GHW and SPW were thoroughly mixed within a single branch of the tree. AMOVA analysis of AFLP data estimated an $\mathrm{F}_{\mathrm{ST}}$ value among the 4 populations of $0.36(s=0.36)$. When calculated in a hierarchical fashion, the $\mathrm{F}_{\mathrm{ST}}$ between the 2 groups of populations was $0.25(s=$ 0.042 ), whereas the $\mathrm{F}_{\mathrm{ST}}$ among populations within groups was $0.41(s=0.040)$.

\section{Chloroplast DNA Sequencing}

We found 1 fixed nucleotide base pair difference between the upper and lower canyon populations in the region between the $\operatorname{trn} L$ (UAA) 5 ' exon and the trnL (UAA) 3 ' exon. The length of this sequence is 548 base pairs and it is designated as "haplotype A" in the lower canyon (Genbank accession number AY786533) and "haplotype B" in the upper canyon (Genbank accession number AY786535). The other region between the trnL (UAA) 3' exon and the $\operatorname{trnF}$ (GAA) exon is 410 base pairs long and had no nucleotide base pair differences among samples (Genbank accession number AY786534).

\section{Pollination Study}

The pollination study was designed to compare seed set from crosses between plants at the same site to that of plants from sites that differ genetically. To do this, it was important to check the seed set of plants that were not manually pollinated. Accordingly, we had several controls, the 1st of which was unbagged "open pollinated" (i.e., pollination by natural pollinators). At GHW we had 19 marked openpollinated plants: 9 survived and 3 set seed $(2$ released seeds before collection and 1 set 35 seeds). At RHF we had 8 plants: 6 survived and all set seed $\left(\bar{x}=14\right.$ seeds $\cdot$ plant $^{-1}, s=$ 3.7). Thus, open-pollination rates were rather erratic.

Bagged plants that were not hand pollinated served as controls to determine the potential for autogamy. At GHW, we had 7 surviving plants of which 2 set seed $(6$ and 4 seeds), but the seeds appeared small, rather flatter than normal, and therefore possibly 


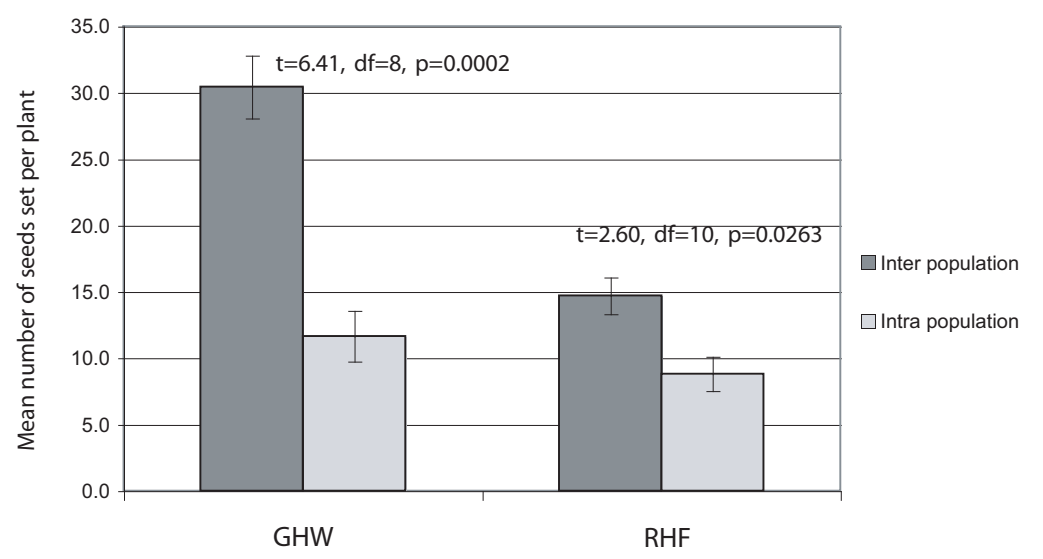

Fig. 3. Mean number of seeds set per plant for interpopulation and intrapopulation crosses of Maguire primrose at 2 sites, GHW and RHF.

TABLE 2. Numbers of plants used for hand-pollination from populations GHW and RHF.

\begin{tabular}{lccccc}
\hline Population & \# Plants pollinated & Herbivory & $\begin{array}{c}\text { Successful } \\
\text { pollinations }\end{array}$ & $\begin{array}{c}\text { \# Surviving } \\
\text { intra-pop crossed }\end{array}$ & $\begin{array}{c}\text { \# Surviving } \\
\text { inter-pop crossed }\end{array}$ \\
\hline GHW & 75 & $39 \%$ & $69 \%$ & 10 & 10 \\
RHF & 62 & $26 \%$ & $76 \%$ & 8 & 14 \\
\hline
\end{tabular}

inviable. We weighed seeds in bulk from unbagged and cross-pollinated plants. The average seed weight was $0.09 \mathrm{mg}$ for cross-pollinated plants and $0.04 \mathrm{mg}$ for those seeds that we judged to be inviable. No sample statistics can be provided because individual seeds were too small to weigh accurately. Of 6 control plants at RHF, only 1 set seed, which again were small and considered inviable.

The final control was to test the ability of plants to self-fertilize by deliberate hand pollination. Of the 5 such hand-pollinated and bagged plants, 2 set seed ( 5 and 7 seeds), but the seeds were again small and possibly inviable. Because even normal-looking seeds of Maguire primrose have yet to be germinated successfully, or tested for viability, we cannot be completely sure that selfing ability is 0 . Thus, there is some doubt associated with the subsequent cross-pollinated treatments. However, given that seed set in the control plants was low and seeds were small, we feel reasonably confident that larger seeds from cross-pollinated plants were indeed a result of hand pollination.

Data from the hand pollinations at both populations are given in Table 2. Twenty-seven percent of our treated plants were influenced by herbivory, which resulted in total destruc- tion of inflorescences. Scat samples were obtained from herbivory sites and determined to be from bushy-tailed woodrats (Neotoma cinerea). The number of hand-pollinated plants that survived was 29 at both populations. Of these, 20 set seed at GHW and 22 at RHF. Plants at both sites set more seed from interpopulation crosses than from intrapopulation crosses and results of $t$ tests suggested that these differences were statistically significant (Fig. 3). All the seed-set levels from controlled crosses were considerably higher than seed set levels from selfed and bagged controls.

For both populations, the ratio of the 2 morphs was nearly 1:1. At GHW we counted 37 pin and 34 thrum plants, and at RHF we counted 24 pin and 26 thrum plants.

Flowering times ranged from 5 April to 7 May 2004 at GHW and from 20 April to 14 May 2004 at RHF (Fig. 4). Therefore, an overlap of 17 days occurred between populations. Both populations appeared to peak twice in their flowering, the 2nd peak of GHW coinciding with the 1st peak at RHF.

\section{Discussion}

If we assume that the 165 loci examined here are representative of neutral markers across the 


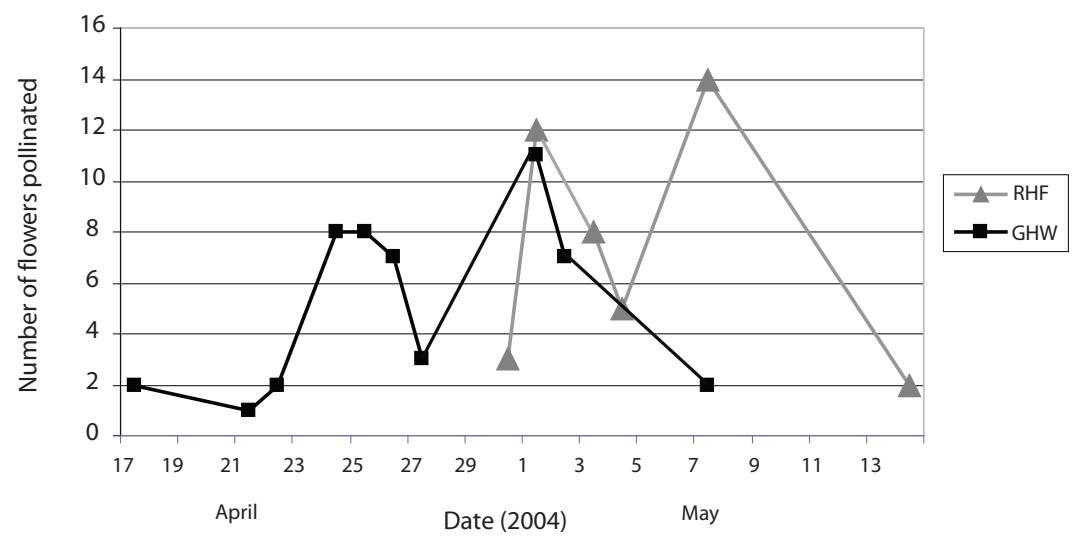

Fig. 4. Number of flowers pollinated at different sampling times as a proxy for the degree of flowering over the 2004 season at 2 sampling sites.

genome as a whole, then our findings indicate that populations of Maguire primrose are highly structured genetically over a relatively narrow range. The $\mathrm{F}_{\mathrm{ST}}$ values estimated from the AFLP data in this study are similar to the those estimated previously (calculated as $\mathrm{G}_{\mathrm{GT}}$ ) using allozyme data (Wolf and Sinclair 1997). Thus, we can infer that the results of the earlier allozyme study were not a function of inadequate locus sampling.

Hamrick and Godt (1996) showed that, on average, endemic species do not have less divergent populations $\left(\mathrm{G}_{\mathrm{ST}}=0.248, s_{\bar{x}}=\right.$ $0.037, n=52$ taxa) than widespread species $\left(\mathrm{G}_{\mathrm{ST}}=0.210, s_{\bar{x}}=0.025, n=87\right.$ taxa $)$. To date, there are no comprehensive meta-analyses of population differentiation $\left(\mathrm{F}_{\mathrm{ST}}\right)$ comparisons among plant species using AFLP data. A similar $\mathrm{F}_{\mathrm{ST}}$ value was estimated for populations of the endangered alpine plant Eryngium alpinum L. by Gaudeul et al. (2000); however, in that study, interpopulation sampling was done at a much larger geographic scale (mean distance between populations $=25 \mathrm{~km}$ ). Jacquemyn et al. (2004) estimated $\mathrm{F}_{\mathrm{ST}}$ values of 0.036 in fragmented populations of Primula elatior spanning sampling distances up to $8 \mathrm{~km}$. Those results indicate considerably less genetic differentiation of $P$. elatior than of Maguire primrose over similar spatial scales. Principal component analysis of AFLP data from Maguire primrose also shows distinct genetic structuring between upper and lower canyon populations and even between populations within the upper and in the lower canyon groups. The considerably higher number of loci provided by the AFLP technique improved resolution of genetic differences among (and within) populations in this study compared to the previous allozyme study (Wolf and Sinclair 1997). All our analyses indicate unusually strong genetic structure of an apparently outcrossing plant over small geographic distances.

One proposed hypothesis explaining the population structure of Maguire primrose is that some populations had passed through a genetic bottleneck, which resulted in divergence through drift. Evidence for a recent bottleneck would be reduced levels of polymorphism in 1 group of populations. GHW, SPW, and RHF had similar levels of polymorphism and only SS had a distinctly lower level. Therefore, the differences between upper and lower canyon populations cannot be explained by the bottleneck hypothesis. SS is the largest population and has been designated the most suitable for use as a seed source (USDA Forest Service 1986). However, if the reduced level of polymorphism at our marker loci is indicative of genome-wide levels, this population may not be the best source for seeds to be used for reestablishment.

The $1 \mathrm{~kb}$ region sequenced from chloroplast DNA had 1 fixed nucleotide difference between samples from upper and lower canyon populations. The fixed difference is probably ancient relative to the current population structure but may have originated in 1 of at least 2 ways. Upper and lower canyon populations could have been separated long enough for base pair substitutions to occur and spread to fixation. Alternatively, the nucleotide polymorphism was 
present in the ancestral population, and after isolation, each population lost alternative alleles. To identify haplotypes in more detail, it would be useful to sequence additional regions in the chloroplast genome that have adequate variation from which to infer population history.

We detected no pollen-stigma incompatibilities between the upper and lower canyon populations. In fact, we detected higher seed set in interpopoulation crosses. The existence of some type of breeding barrier between populations would have been supported if interpopulation matings produced significantly fewer seeds than intrapopulation matings. Our finding of higher seed set from the interpopulation crosses suggests the possibility of inbreeding depression. Unfortunately, it is not known if seeds from our hand-pollinated plants are viable. Thus, we are unable to rule out any postzygotic reproductive barriers. Examining offspring performance would be difficult because no one has been able to germinate Maguire primrose seeds ex situ. Failure of seed germination may be due to substrate dependence and other ecological factors.

When considered in combination with the physical distance between the populations, the relatively short overlap in flowering times between populations could serve to restrict and isolate populations. This may explain the apparent lack of current gene flow but does not give the actual cause of population divergence. However, it is possible that flowering time differences were larger in the past and that this could have led to the current level of differentiation (Stamm 1983).

Foraging range of insect pollinators is unlikely to be a limiting factor in the amount of gene flow between populations. During the course of this study, the observed visitors of Maguire primrose were bumblebees (Bombus centralis) and hover flies (Syrphidae epistrophe). Although bumblebees can make single flights of several kilometers (Dramstad 1996), it is unknown if a large proportion of total foraging bouts would entail such distances (Osborne et al. 1999).

Heterostylous populations can often diverge from equal morph frequencies in small populations by random chance (Byers 1995, Endels et al. 2002). A significant disproportion of morph types could cause breakdown of the mating system. This instability would then be followed by an increase of self-compatible homostyles and further lead to severe inbreeding depression and possible extinction (Washitani 1996). Other extinction risks to heterostylous populations stem from a vulnerability to the effects of inbreeding (Ellstrand and Elam 1993) such as low pollen quantity (Byers 1995) and an insect pollen vector requirement that can result in a reduced proportion of potential mates (Washitani 1996). We found that floral morph types of Maguire primrose were approximately equal at each population, and therefore, the lower seed set at RHF is likely not due to a lack of compatible mates (Ishihama et al. 2003).

A universal problem with testing evolutionary hypotheses is distinguishing the events and conditions under which patterns evolved from the forces needed to maintain such patterns. Several historical scenarios could explain the origin of genetic differences between upper and lower canyon primrose populations. All require some form of reproductive isolation. The most likely are long-term differences in phenology and geographical isolation during glaciation. If the ancestors of what are now upper and lower canyon populations were isolated in different (local) glacial refugia, there may have been sufficient time for differentiation through genetic drift. It now appears that populations may be coming back into secondary contact, so 1 possible evolutionary trajectory is eventual hybridization and reintegration of the 2 groups of populations. Whether resulting hybrid populations are suitably adapted to the current habitat is a question worth pursuing once we learn to germinate and raise seedlings.

\section{Summary}

Maguire primrose is a local endemic, unique in its ecological and physiological requirements. Therefore, whether it is recognized as a distinct species or a varietal form of $P$. cusickiana, Maguire primrose is still an important target for conservation. From our study of genetic variation and breeding system, we infer the following: (1) the results from increased sampling of loci support previous results using only 4 loci: nearby populations of Maguire primrose are highly differentiated genetically; (2) we found no evidence of a genetic bottleneck to explain differences between the upper and lower canyon areas; (3) we detected a single nucleotide difference in chloroplast DNA suggesting that the current genetic structure has 
been stable for a sufficiently long period to allow for allele fixation; (4) we found no breeding barriers between upper and lower canyon populations, so pollen-stigma interactions can explain neither the origin nor the maintenance of the observed genetic structure; and (5) flowering times between the upper and lower canyon overlapped to some degree but could be sufficiently different to explain reproductive isolation when the effect is combined with physical distance. Furthermore, if flowering times were even more distinct in the past, genetic differentiation could have occurred via drift.

\section{ACKNOWLEDGMENTS}

We thank the U.S. Fish and Wildlife Service and the USDA FS Wasatch-Cache National Forest for granting the necessary collecting permits and the USDA FS Wasatch-Cache National Forest for financial assistance. We also thank Mike Duncan and Larry England for logistical help, and M. Winston Ellis, Leila Shultz, Mike Pfrender, Carol Rowe, and Aaron Duffy for comments on the manuscript.

\section{Literature Cited}

Beedlow, P., J. Carter, and F. Smith. 1980. Primula maguirei L. Wms. (Primulaceae), a preliminary report on the population biology of an endemic plant. U.S. Fish and Wildlife Service, Salt Lake City, UT. 3 pp.

Benham, J., J.U. Jeung, M. Jasieniuk, V. Kanazin, and T. BLAKE. 1999. Genographer: a graphical tool for automated flourescent AFLP and microsatellite analysis. Journal of Agricultural Genomics 4: Article 4.

Byers, D.L. 1995. Pollen quantity and quality as explanations for low seed set in small populations exemplified by Eupatorium (Asteraceae). American Journal of Botany 82:1000-1006.

DaRwIN, C. 1877. The different forms of flowers on plants of the same species. John Murray, London.

Doyle, J.J., AND J.L. DoyLe. 1987. A rapid DNA isolation procedure for small quantities of fresh leaf tissue. Phytochemical Bulletin 19:11-15.

Dramstad, W.E. 1996. Do bumblebees (Hymenoptera: Apidae) really forage close to their nests? Journal of Insect Behavior 9:163-182.

Ellstrand, N.C., And D.R. Elam. 1993. Population genetic consequences of small population size-implications for plant conservation. Annual Review of Ecology and Systematics 24:217-242.

Endels, P., H. Jacquemyn, R. Brys, and M. Hermy. 2002. Changes in pin-thrum ratios in populations of the heterostyle Primula vulgaris Huds.: does imbalance affect population persistence? Flora 197:326-331.

Excoffier, L., P.E. Smouse, and J.M. Quattro. 1992. Analysis of molecular variance inferred from metric distances among DNA haplotypes: application to human mitochondrial DNA restriction data. Genetics 131:479-491.

Gaudeul, M., P. Taberlet, and I. Till-Bottraud. 2000. Genetic diversity in an endangered alpine plant, Eryngium alpinum L. (Apiaceae), inferred from amplified fragment length polymorphism markers. Molecular Ecology 9:1625-1637.

Gitzendanner, M.A., And P.S. Soltis. 2000. Patterns of genetic variation in rare and widespread plant congeners. American Journal of Botany 87:783-792.

Hamrick, J.L., AND M.J.W. GodT. 1996. Effects of life history traits on genetic diversity in plant species. Philosophical Transactions of the Royal Society of London Series B. Biological Sciences 351:1291-1298.

Holmgren, N.H., and S. Kelso. 2001. Primula cusickiana (Primulaceae) and its varieties. Brittonia 53: $154-156$.

Ishihama, F., C. Nakano, S. Ueno, M. Ajima, Y. Tsumura, AND I. WASHITANI. 2003. Seed set and gene flow patterns in an experimental population of an endangered heterostylous herb with controlled local opposite-morph density. Functional Ecology 17:680-689.

JacQuemyn, H., O. Honnay, P. Galbusera, and I. RoldanRuIz. 2004. Genetic structure of the forest herb Primula elatior in a changing landscape. Molecular Ecology 13:211-219.

Maki, M., H. Morita, S. Oiki, and H. TaKahashi. 1999. The effect of geographic range and dichogamy on genetic variability and population genetic structure in Tricyrtis section Flavae (Liliaceae). American Journal of Botany 86:287-292.

Miller, J., M. LitvaK, S. Kelso, and A. Vargo. 1994. Comparative reproductive biology of two alpine primrose species. Arctic and Alpine Research 26:297-303.

Miller, M. 1997. Tools for population genetic analysis (TFPGA), v1.3: a windows program for the analysis of allozyme and molecular population genetic data [software]. Mark Miller's Analytical Software Page. Available from: http://www.marksgeneticsoftware.net/.

MotTEn, A.F. 1982. Autogamy and competition for pollinators in Hepatica americana (Ranunculaceae). American Journal of Botany 69:1296-1305.

Nei, M., T. Maruyama, and R. Chakraborty. 1975. The bottleneck effect and genetic variability in populations. Evolution 29:1-10.

Osborne, J.L., S.J. Clark, R.J. Morris, I.H. Williams, J.R. Riley, A.D. Smith, D.R. Reynolds, and A.S. EDWARDS. 1999. A landscape-scale study of bumble bee foraging range and constancy, using harmonic radar. Journal of Applied Ecology 36:519-533.

PadgetT, W.G. 1986. Maguire primrose status report [unpublished]. Utah Native Plant Society, Logan.

RHOLF, F. 1989. NTSYS-pc: numerical taxonomy and multivariate analysis system [software]. Exeter Software, Setauket, NY. Available from: http://www.exetersoftware.com/cat/ntsyspc/ntsyspc.html

Schneider, S., D. Roessli, And L. Excoffier. 2000. Arlequin ver. 2.000: a software for population genetics data analysis [software]. Available from: http://gb .unige.ch/arlequin/.

STAMM, P. 1983. The evolution of reproductive isolation in closely adjacent plant populations through differential flowering time. Heredity 50:105-118.

Taberlet, P., L. Gielly, G. Pautou, and J. Bouvet. 1992. Universal primers for amplification of three noncoding regions of chloroplast DNA. Plant Molecular Biology 17:1105-1109. 
USDA Forest Service. 1986. Management plan for Primula maguirei. USDA Forest Service, Ogden, UT.

U.S. Fish AND Wildlife Service. 1985. Endangered and threatened wildlife and plants; final rule to determine Primula maguirei (Maguire primrose) to be a threatened species. Federal Register 50:33731-33737.

Vos, P., R. Hogers, M. Bleeker, M. Reijans, T. van de Lee, M. Hornes, A. Frijters, et Al. 1995. AFLP: a new technique for DNA fingerprinting. Nucleic Acids Research 23:4407-4414.

Washitani, I. 1996. Predicted genetic consequences of strong fertility selection due to pollinator loss in an isolated population of Primula sieboldii. Conservation Biology 10:59-64.

WEIR, B.S. 1996. Genetic data analysis II. Sinauer Associates, Sunderland, MA.
Weir, B.S., And C.C. Cockerham. 1984. Estimating Fstatistics for the analysis of population structure. Evolution 38:1358-1370.

Williams, L.O. 1936. Revision of the western primulas. American Midland Naturalist 17:741-748.

Wolf, P.G., B. Doche, L. Gielly, and P. Taberlet. 2004. Genetic structure of Rhododendron ferrugineum at a wide range of spatial scales. Journal of Heredity 95: 301-308.

WOLF, P.G., AND R.B. SinCLAIR. 1997. Highly differentiated populations of the narrow endemic plant Maguire primrose (Primula maguirei). Conservation Biology $11: 375-381$.

Received 25 October 2006 Accepted 6 August 2007 